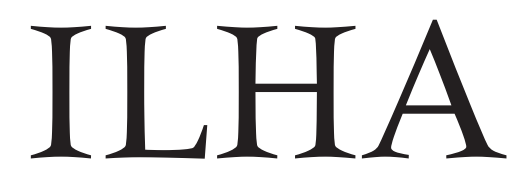

\title{
Revista de Antropologia
}

Florianópolis, volume 15, números 1 e 2 janeiro a dezembro, 2013 
ILHA - Revista de Antropologia, publicação do Programa de Pós-Graduação em Antropologia Social (PPGAS) da Universidade Federal de Santa Catarina.

Universidade Federal de Santa Catarina

Reitora: Prof. a Roselane Neckel

Diretor do Centro de Filosofia e Ciências Humanas: Prof. Nazareno Jose de Campos

Coordenador do PPGAS: Prof. a Alícia Norma Gonzalez de Castells

Coordenação Editorial Evelyn Martina Schuler Zea, Gabriel Coutinho Barbosa e Maria Eugenia Dominguez

Editores do Volume Evelyn Martina Schuler Zea, Gabriel Coutinho Barbosa e Maria Eugenia Dominguez

Editor de Resenhas Marcos Aurélio da Silva

Editora Gerente Daniela Fany Hess

Conselho Editorial Alberto Groisman, Alicia Norma Gonzalez de Castells, Antonella Maria Imperatriz Tassinari, Carmen Silvia Rial, Edviges Marta Ioris, Esther Jean Langdon, Evelyn Martina SchulerZea, Gabriel Coutinho Barbosa, Ilka Boaventura Leite, Jeremy Paul Jean LoupDeturche, José Antonio Kelly Luciani, Maria Eugenia Dominguez, Maria Regina Lisboa, Márnio Teixeira-Pinto, Miriam Hartung, Miriam Pillar Grossi, Oscar Calavia Saez, Rafael José de Menezes Bastos, Rafael Victorino Devos, Scott Correll Head, Sônia Weidner Maluf, Theophilos Rifiotis e Vânia Zikán Cardoso

Conselho Consultivo BozidarJezenik, Universidade de Liubidjana, Eslovênia; Claudia Fonseca, Universidade Federal do Rio Grande do Sul; Cristiana Bastos, Universidade de Lisboa, Portugal; David Guss, Universidade de Tufts, Estados Unidos; Fernando GiobelinaBrumana, Universidade de Cádiz, Espanha; Joanna Overing, Universidade de St. Andrews, Escócia; Manuel Gutiérrez Estévez, Universidade Complutense de Madrid, Espanha; Mariza Peirano, Universidade de Brasília; Marc-Henri Piault, Escola de Altos Estudos em Ciências Sociais, França; SoheilaShashahani, ShahidBeheshtiUniversity, Irã; Stephen Nugent, Universidade de Londres, Inglaterra

Projeto gráfico Isabela Benfica Barbosa

Editoração eletrônica Annye Cristiny Tessaro (Lagoa Editora)

Revisão Patricia Regina da Costa (português) e Rafaela Marques (espanhol)

Catalogação na fonte pela Biblioteca Universitária

Ilha - Revista de Antropologia / Universidade Federal de Santa Catarina. Programa de Pós-Graduação em Antropologia Social. v. 15, números 1 e 2 (2013) - Florianópolis: UFSC/ PPGAS, 2013 - 400 pp.

ISSN 1517-395X

1. Antropologia 2.Periódico 1. Universidade Federal de Santa Catarina

ISSN

$1517-395 X$

Solicita-se permuta/Exchange desired

As posições expressas nos textos assinados são de responsabilidade exclusiva de seus autores.

Toda correspondência deve ser dirigida à Comissão Editorial da Revista Ilha Programa de Pós-Graduação em Antropologia, Centro de Filosofia e Ciências Humanas - CFH Universidade Federal de Santa Catarina

Campus Universitário - Trindade

88040-970 - Florianópolis - SC - Brasil

Fone/fax: (48) 3721-9714

E-mail: ilha.revista@gmail.com sítio: http://www.periodicos.ufsc.br/index.php/ilha

Todos os direitos reservados. Nenhum extrato desta revista poderá ser reproduzido, armazenado ou transmitido sob qualquer forma ou meio, eletrônico, mecânico, por fotocópia, por gravação ou outro, sem a autorização por escrito da comissão editorial. 


\title{
SUMÁRIO
}

\author{
NÚMERO 1
}

Recintos de Laboratório, Evolução

Darwiniana e Magia da Obliteração -

Reflexões em Antropologia da Ciência e da

Modernidade

Etnicidade na Amazônia Antiga:

JONATHAN HILL

reconstruindo identidades do passado por

meio da arqueologia, da linguística e da

etno-história

O Riso e o Medo Tupi

LEIF GRÜNEWALD

O Riso como Forma de Produção da "Vida

Sossegada"

ALEXANDRE HERBETTA

Alimentos, Reciprocidade e Fluxos: sobre a

lógica da alternância nos andes peruanos

Pessoas que Cruzam Territórios e

JORGE CLADERA

Territórios que são Pessoas - As

Experiências do Direito Espacial nos

Andes: um estudo de caso no noroeste

argentino

NÚMERO 2

De Encontros nos Corpos Guarani

Conflito, Resignação e Irrisão na 
El Circo de Buenos Aires y sus Prácticas: 277

JULIETA INFANTINO

definiciones en disputa

Megaeventos e Unidades de Polícia

Pacificadora: representações sobre o lugar

das favelas no tecido urbano

A Fronteira entre Trabalho e Emprego:

331

LETÍCIA DE FARIA FERREIRA E notas sobre atividades paralelas no Pampa Gaúcho

JUSSEMAR WEISS GONÇALVES

\section{Resenhas}

BUTLER, Judith. Dar cuenta de sí mismo:

violência ética y responsabilidade.

MERCANTE, Marcelo S. Imagens de cura:

Ayahuasca, imaginação, saúde e doença da Barquinha.

ANTONIO, Andrea Tochio de. O psicólogo

antropológico da cirurgia plástica.

REZENDE, Claudia Barcellos; COELHO,

WALESKA DE ARAÚJO Maria Claudia. Antropologia das emoções. AURELIANO

PORTELA GUARIN, Hugo. La

Epidemiología Intercultural:

argumentaciones, requerimientos y

propuestas.

LANGDON, Esther Jean; Everton Luís

Pereira (Org.). Rituais e performances: iniciações em pesquisa de campo.

Dissertações e teses defendidas em 2013 no PPGAS/UFSC 
NÚMERO I 
